\title{
PAEDIATRIC LESSONS FROM THE PAST
}

\section{"Of stupidity or folly": Thomas Willis's perspective on mental retardation}

A N Williams

Arch Dis Child 2002;87:555-558

"Mental retardation" is a modern term for an age old problem. The descriptions of paediatric cases contained within the works of Thomas Willis (1621-75) have been increasingly recognised for their insight into seventeenth century child health practices.

1

$\mathrm{n}$ two of his major works Willis comments on mental retardation; this review illustrates from his writings his understanding and management of this condition.

Thomas Willis (1621-75), Sedleian Professor of Natural Philosophy at Oxford and a founding Fellow of the Royal Society, left a body of work that defined mid seventeenth century medicine. ${ }^{1}$ He is credited with inventing the word neurology. ${ }^{2}$ He is rightly remembered primarily for his astute observations of adult neurological conditions and for describing the functional significance of the arterial anastemosis at the base of the brain, now immortalised with his name.

Recent interpretations of Willis's work have led to a growing appreciation of his significant contributions to paediatric neurology, a specialty founded approximately three centuries after his death. A previous paper has concentrated on his paediatric neurology cases. ${ }^{3}$

Willis's writings afford a fascinating insight into the clinical rationale of the seventeenth century physician in their management of paediatric cases.

Given our own limited understanding of mental retardation, Willis's work is a poignant reminder of the challenges we face three centuries later.

\section{MENTAL RETARDATION}

The phrase "learning difficulty" is far less pejorative and stigmatising than the term "mental retardation" used by both the ICD-10 and the DSM-IV.TR. ${ }^{4}{ }^{5}$ In the UK "learning difficulty" is used synonomously with mental retardation, but in the United States it is used to refer to what were known as "specific learning difficulties", that is, dyslexia.

Thus our use of the term "learning difficulty" in this wider context may be more dishonest than the term "stupidity" used by Willis. Certainly in our own practice none of us would dare to use Willis's term. Irrespective of the definition, mental retardation is still a challenging aspect of paediatric care, with most cases still having no definable cause or effective treatment. ${ }^{6}$

However, the seventeenth century view was very different from that held today and surprisingly, perhaps, more compassionate: "Fools were considered to be marked out by God and not stricken by disease" ${ }^{\prime \prime}{ }^{7}$

Willis's first published description of mental retardation was in his Cerebri Anatome (1664), his monumental work on comparative brain anatomy. In it he presented a case of a child demonstrating cerebral atrophy (fig 1) who is described as being "foolish from birth".

\section{SUBSEQUENT DESCRIPTIONS}

In 1663 or 1664 Willis gave a series of lectures, which were attended by the philosopher John Locke (1632-1704) and by the natural philosopher and chemist Robert Boyle (1627-1691), both of whose notebooks still survive. In a lecture on Sleep and Wakefullness, Boyle recounts Willis's description of an autistic savent:

\section{"I have heard of an idiot in the County of Suffolk who accustomed to watch and count the chimes of clocks and bells, could with complete certainty tell the hour of the day without any clock: Indeed he could tell the quarter just as if he had consulted a watch. He could do this in the fields beyond the sound of the bell, by simply murmuring to himself and imitating the sound of a clock."}

In his lectures Willis hypothesised that stupidity was caused by exhausted animal spirits that affected the imagination and memory. ${ }^{10}$ He subsequently developed his argument at some length in a later work "de anima Brutorum" ("Of the Soul of Brutes") (1672). In it he devoted an entire chapter to mental deficiency, entitled "Instructions and Prescripts for the cure of Stupidity or Folly". ${ }^{11}$ This is one of the earliest systematic descriptions of mental deficiency. ${ }^{12}$

Although other commentators reviewing the chapter have interpreted the folly section as indicative of schizophrenia, ${ }^{13}$ there have been few other comments on Willis's description of stupidity-mental retardation. Indeed the only long term influence of this chapter was Willis's description of an adult case of "stupidity" which had resolved after a fever; in later centuries this gave rise to fever therapy or inoculation with malaria. $^{14}$

Willis's thoughts were heavily influenced by Pierre Gassendi (1592-1655) whom he frequently cited. Indeed the title "de anima brutorum" (the Soul of Brutes) reflects a direct influence of Gassendi's writings. Gassendi claimed that animals must have souls since they show evidence of 
$P \rightarrow 0^{\circ} \quad r y=$

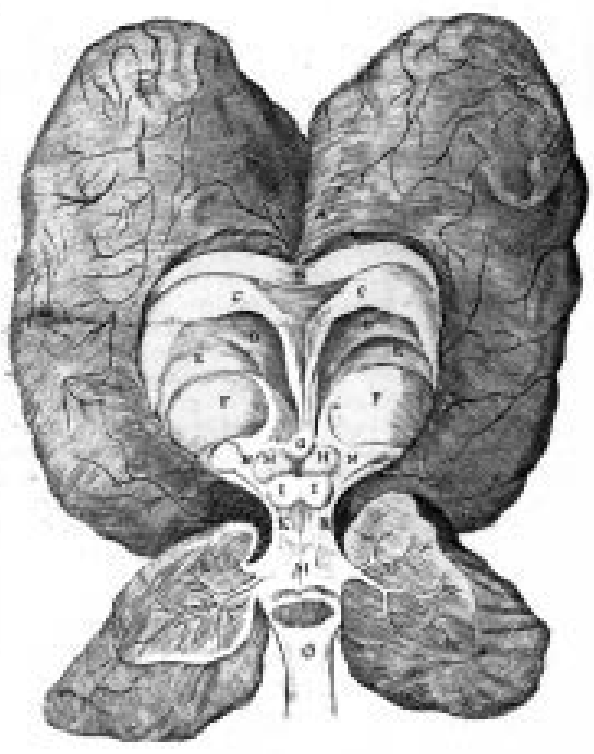

The Foarth Figure.

The Effigies of a bravene Brein of a certais Y tath that war foolifb from bì birth, and

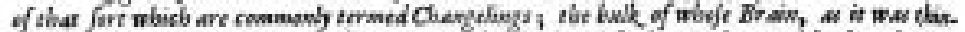

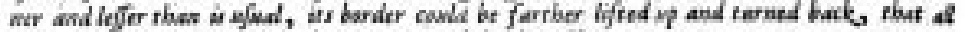

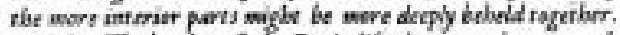

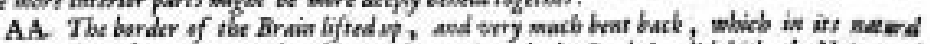
fire, heing buit ro the sblung Marress, migh the Cerebol, did hide the Nates asd Teftes.

B. The border or inferiar margent of the callow Bon

CC. The Fornix, with its rwo Arwow, emirraciug the phante of the shlong Marrow.

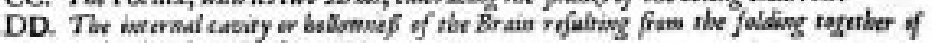
irs barder about the ebisur Merrstw.

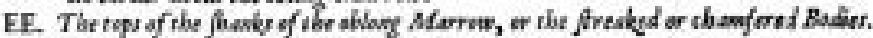

FF. The Chaswers of the Optick 2 proes.

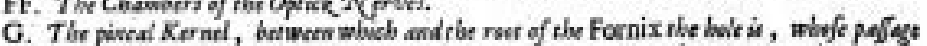

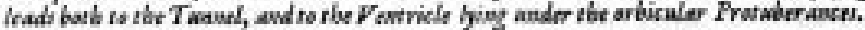

HH. The Protudernaces called Nates.

II. Tbe Prormberacen called Teftes.

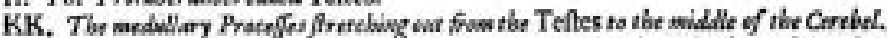

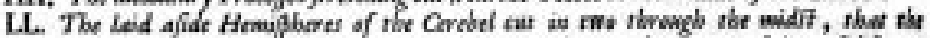

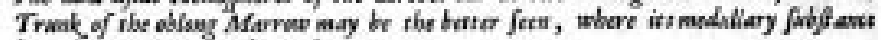
brancives out iats to for form of atres.

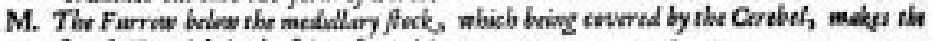
fourb Ventricle ia ibe forw of a writing pow.

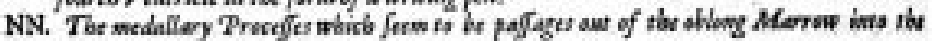
embicalar Pratmberasent.

O. The endef the stitong Marrew giving plase te the phivat.

Figure 1 Plate of congenital cerebral atrophy and its accompanying text (with permission from the Wellcome Library, London).

memory, reason, and similar traits. ${ }^{13}$ Gassendi called this the Soul of Brutes, which is also present in man, as an inferior soul in whom there is also a superior or rational soul. Willis's distinction between foolishness and stupidity was in essence the presence of a thought disorder in the former.

"Stupidity or folly, tho it chiefly belongs to the rational Soul, and signifies the defect of the Understanding and Judgement, nevertheless it is not improperly placed among the Diseases of the Head or of the Brain: to wit as much as that Eclips of the superior soul, proceeds from the Imagination and the Memory [being] injured: and the failing of these depends upon the faults of the animal Spirits, and of the Brain it self." ${ }^{\prime 1}$

Willis believed that stupidity was not only caused by exhausted animal spirits affecting the imagination and memory; he clearly pointed out "that the brain itself is found to be first in fault". ${ }^{11}$ He commented on how brain size, shape, texture, and "evil conformation of the Brain as to its pores and passages" were important causes and affected the function of the brain, the spirits, or both.

\begin{abstract}
"Persons that are stupid we may imagine, sometimes an excess of some manifest quality in the Brain, as chiefly of moisture and cold, for which reason Children and aged Persons are often wont to be affected with a Dulness of the Senses: sometimes a texture too gross and earthy, so that the Spirits cannot easily irradiate it, or make Tracts for themselves. To this gross Texture of the Brain some born of Rusticks are frequently obnoxious, so that in some Families looking back up on many generations, you will scarce find one wise or witty man."11
\end{abstract}

Willis's categorisation of the degrees of stupidity as "some persons are accounted unfit as to the comprehension of all things, Others only to some" ${ }^{\prime 11}$ is expanded further by him (table 1).

Interestingly, in an earlier translation, also by Pordage (1683), "learning" was expanded to "learning of letters" - that is, reading and writing, thereby adding a wider interpretation of the different learning difficulties as defined by Willis within his first category.

\section{CAUSAL FACTORS}

In our present day practice a detailed history is recognised as the most important component in any paediatric assessment. ${ }^{16}$

Willis clearly recognised and described many different causes: hereditary, congenital, and acquired. He recognised the hereditary nature "as when fools begat fools-the reason to wit is clear enough, to wit the same weak particles flowing from the constituting animal organs in the son, which were in the father". ${ }^{11}$

But Willis also felt that the cause could be accidental: "It frequently happens that wise and might ingenious men, beget mere sots, which sometimes so fall out for these reasons. Either that the Parents spend their Spirits in Study and too much thinking, or weaken and enervate the Body through intemperance, luxury and ill living." ${ }^{11}$

Willis supported this with his opinion regarding parental factors:

"Those who are born of parents broken with old age, or of such as are not yet ripe or are too young, or of drunkards, soft or effeminate men, want a great and liberal ingenuity or wit. Nor does there happen a less detriment to them of the Animal Faculty whose fires are

Table 1 Willis's Degrees of Stupidity"

(1) "Some being wholly unfit for Learning, and the liberal Sciences are apt enough to mechanical arts."

(2) "Others, tho incapable of both these, yet readily comprehend Agriculture and Country Affairs."

(3) "Others incapable in a manner of all business, can be taught only those things that regard eating and drinking, and the common way of living."

(4) "Others being mere Dolts, scarce understand any thing at all, or do any thing with Knowledge." 
obnoxious to evil attentions of the brain as the palsie, Epilepsie, Carus [insensibility], convulsions and the like so that to be born of parents who have a sound mind in a sound body is far beyond a large patrimony. "11

Willis clearly distinguished between congenital and acquired causes. He recognised that head injuries, irrespective of age, could have adverse sequelae:

"Sometimes a great wound or concussion of the head, especially which happens by falling headlong from an high place, brings a prejudice and weakness to the animal faculty, dulling the understanding. ${ }^{\prime 8}$

In the 1683 Pordage translation, he also relates a history of developmental regression following the onset of fits:

"I knew a young maid, at first of an acute wit, and lively ingenuity, who after she had long laboured with the Falling Sickness, became sottish and Foolish, like a changeling. ${ }^{115}$

\section{WILLIS'S PROGNOSIS}

Willis's prognosis is mixed but nevertheless guarded:

"As to the Prognostick, Stupidity contracted by birth, or hereditary, or hapning through some unknown cause, if it continues to the time of Puberty, is scarce ever cured: tho sometimes it happens that little Children, at first dull and almost senseless, when the Crases of the Brain and Spirits come afterward to a maturation, become ingenious and apt enough to learn.

The disease raised through some evident Cause as by a hurt of the Head, or a violent Passion, also hapning upon an inveterate Epilepsy, if it persevers for some time, is afterward incurable." 11

However Willis hypothesised the role of a similar remedy that he prescribed for Lethargy as a means of curing stupidity. The rationale being to allow animal spirits "free from any deadness and stupefaction" to make "pores and passages" within the brain and thereby expand themselves within it. ${ }^{8}$

He mentioned two adult cases where fever has sometimes "cur'd some fools and stupid person" rationalising that "the reason of which seems to be, that the Febrile heat sometimes rarifies and disperses the mist investing the brain". ${ }^{11}$

\section{WILLIS'S GENERAL MANAGEMENT}

Willis had many suggestions for the assistance of parents or carers. Neither did he restrict his advice to medical matters alone. Willis was an advocate of medicine and education but emphasised the limits of what he had to offer and how medicine and education must work together.

"As to what respects the cure of this Disease, Stupidity, whether innate or acquir'd (if it not be a plain senselessness, and doltishness incapable of all Erudition) though it be not usuall be cured, yet it is want to be amended. Wherefore the care both of a Physician and Tutor, must be used for polishing somewhat the Understanding of such as are affected, and that being brought to the use of at least some little Reason, they may be exempted from the rank of Brutes." 11

Willis advocated a strict educational programme:
"Therefore they are to be instructed in all things by an assiduous and very diligent Master, and the same things are to be inculcated again and again. For my this means the Spirits, tho dull and torpid, will in some measure be actuated by perpetual Exercise: and being continually stirred up, will make at length for their Expansion some Tracts or passages, tho imperfect, in the Brain, how gros soever."11

Paediatricians are extremely familiar with different educational programmes and their proven/unproven benefits for specific categories of childhood educational difficulties. Of course, Willis's concepts are based on the foundation of Spirits, which long ago lost credibility and passed from mainstream medical practice. (Osler described the remedies advocated as a consequence of this system as "being as dead as Willis". ${ }^{17}$ ) However, Willis's explanation of the expansion of imperfect passages in the brain to restore a deficient function, through a programme of active stimulation does perhaps suggest some seventeenth century view on remodeling in the brain as a consequence of environmental stimulation.

The medical treatment aims were to "purifie and vilatize the Blood and nervous Liquor, together with the Animal Spirits: and also that they may clarifiei the Brain and render it more Diaphanous".${ }^{11}$ He recommended a light diet, dry habitat, and moderate sleep.

Willis also commented on more drastic measures: "Moreover, it is on this account that some mightily extol trepanning, (to wit, whereby the Brain may transpire and evaporate more clearly)". ${ }^{11}$

Finally, Willis finally cautioned about the futility of prolonged treatments when there had been no change: "it will be in vain to waste any more physival Oyle and Labour" but adds "if after the use of those things signs of benefit, or some hope appear, sometimes it seems proper to add altering Remedies, to be taken daily at Physucal hours for a long time". ${ }^{11}$

Willis concluded by emphasising that there were many other treatments available, none of which he felt able to recommend:

"I could add here many other Medicines and wayes of Administration: but let these suffice in a case almost desperate, where most commonly no remedies do good, and the Cure is never perfected." ${ }^{11}$

\section{MENTAL RETARDATION SINCE WILLIS}

Stupidity (lack of intelligence) has always been associated with "mental retardation". ${ }^{19}$ Previous commentators in historical reviews have considered that serious consideration to the causes of mental retardation started from the nineteenth century, with the work of Down dividing severe mental disability into three groups: the congenital, accidental, and developmental. ${ }^{18}$

This review presents evidence from Robert Boyle's notes of Willis's lectures, Willis's writings on comparative brain anatomy, and his chapter "on folly or stupidity" in his De Anima Brutorum of his management of mental retardation. Willis had a clear concept of mental retardation two centuries before Down, and clearly differentiated hereditary from congenital and acquired factors, as well placing them within a medical framework based on the contemporary understanding of the workings of the central nervous system.

Over the past one hundred years the same fundamental problem has been given a variety of different terms, including "mental retardation", "mental handicap", "minimal cerebral dysfunction", "learning difficulty", and "learning disability".

The debate regarding appropriate terminology around mental retardation is far from closed, with calls still being made for all child heath and educational professionals to use the same 
language the same way. ${ }^{18}$ Bax and MacKeith summarised this eloquently in 1963: "First and foremost, surely is how careful we must be in our use of language. If words are used ... [that] confuse us they may in fact harm the patient."19

Three hundred and fifty years after Willis, modern medical science may have a greater understanding of the causes of mental retardation, but problems still arise because of the incorrect use of terminology.

\section{ACKNOWLEDGEMENTS}

I would like to thank Dr M Holloway, Dr R Sunderland, and Dr C Essex for their comments. I would like to acknowledge the referees for their comments; and also the support of the Centre for the History of Medicine, Medical School, University of Birmingham in the writing of this paper.

\section{Author's affiliation}

A N Williams, North Warwickshire PCT, UK

\section{REFERENCES}

1 Dewhurst K. Thomas Willis and the foundations of British neurology. In Rose FC, Bynum WF, eds. Historical aspects of the neurosciences. New York: Raven Press, 1982:327-44.

2 Hughes JT. Pioneers in neurology: Thomas Willis (1621-1675) Neurol 2000;247: 151-2.

3 Williams AN, Sunderland R. Thomas Willis: the first paediatric neurologist? Arch Dis Child 2001;85:506-9.

4 WHO. ICD-10. Classification of mental and behavioural disorders, clinical descriptions and diagnostic guidelines. Geneva: World Health Organisation, 1992.

5 American Psychiatric Association. Diagnostic and statistical manual (text revision) (DSM-IV TR). Washington, DC: American Psychiatric Association, 2000
6 Whiting K. Investigating the child with learning difficulty. Curr Paediatr 2001;11:240-7.

7 Dewhurst K. Thomas Willis Oxford lectures. Oxford: Sandford Publications, 1980:160.

8 Willis T. Plate 70: Anatomy of the brain and text. The remaining medical works of that famous and renowned physician Dr Thomas Willis ... with eighteen copper plates. London: printed for T Dring et al, 1681

9 Boyle. Royal Society Papers 19, ff, 9-13.

10 Dewhurst K. Thomas Willis Oxford lectures. Oxford: Sandford Publications, 1980:137.

11 Willis T. Chapter IX, Instructions and Precepts for the cure of Stupidity or Folly. In: The London Practice of Physick, translated by Samuel Pordage. London: printed for Thomas Basset and William Crooke, 1685:489-94.

12 Cranefield PF. A seventeenth century view of mental deficiency. Bull Hist Medicine 1961;XXXV:291-316.

13 Isler H. Thomas Willis (1621-75), doctor and scientist. New York/London: Hafner, 1968:165.

14 Zilboorg G, Henry GW. A history of medical psychology. New York, 1941:266.

15 Willis T. Two discourses concerning the Soul of Brutes ... Englished by S. Pordage, London, Dring, Harper, and Leight 1683. Cited in Cranefield PF, A seventeenth century view of mental deficiency. Bull Hist Med 1961;XXXV:291-316.

16 Newton RW, Wraith JE. Investigation of learning difficulty. Arch Dis Child 1995;72:460-5.

17 Viets HR. A Patronal festival for Thomas Willis (1621-1675) with remarks by Sir William Osler. Bart. FRS. Ann Med Hist 1917;1:118-24.

18 Whitmore K, Bax M. What do we mean by SLD? A historical perspective. In: A neurodevelopmental approach to specific learning disorders. Clinics in Developmental Medicine No. 145. Cambridge University Press, MacKeith Press, 1999:1-23.

19 Bax M, MacKeith R. Foreward. Minimal cerebral dysfunction: Papers from the International Study Group held at Oxford, September 1962 Clinics in Developmental Medicine No. 10. London: Spastics International Medical Publications/William Heinemann Medical Books 1963.

\section{ARCHIVIST}

\section{Tics and psychiatric symptoms}

M ost studies of psychiatric problems in children with tics have included only children referred to clinics. There have been few community based studies and those that have been reported have used parent reports the validity of which has been questioned. The association between tics, attention-deficit-hyperactivity disorder (ADHD), and psychiatric symptoms has been investigated using teacher reports in three areas of the United States (Missouri, Wisconsin, and Long Island, New York) (Kenneth D Gadow, et al. Developmental Medicine and Child Neurology 2002;44:330-8).

The study included 3006 children: 413 preschool (age 3-5 years, attending private preschool and day care centres or Head Start programmes, 237 boys), 1520 elementary school (age 5-12 years, 787 boys), and 1073 secondary school (age 12-18 years, 573 boys). They were assessed by teachers using a Diagnostic and Statistical Manual of Mental disorders 4th edition (DSM-IV)-referenced behaviour rating scale appropriate to age. Children were divided into four groups: ADHD with tics (128), ADHD without tics (220), tics without ADHD (125), and neither tics nor ADHD (2533).

The prevalence of tics, with or without ADHD, decreased with age (preschool 22\%, elementary school $8 \%$, secondary school 3\%). Both tics and ADHD were more common in boys at all ages. Most psychiatric symptoms (including oppositional defiant disorder, conduct disorder, and generalised anxiety disorder) were most prevalent in children with ADHD (ADHD + tics > ADHD alone $>$ tics alone $>$ neither) but obsessive-compulsive disorder and phobias were most prevalent in children with tics.

Tics are common in preschool children and become less common as childhood progresses. Most psychiatric symptoms have a greater association with ADHD than with tics but obsessive-compulsive disorder and phobias have a greater association with tics than with ADHD. 